\title{
Intra-Amygdala Muscimol Injections Impair Freezing and Place Avoidance in Aversive Contextual Conditioning
}

\author{
Matthew R. Holahan ${ }^{1,2}$ and Norman M. White \\ Department of Psychology, McGill University, Montréal, Québec H3A 1B1, Canada
}

\begin{abstract}
Rats were trained by shocking them in a closed compartment. When subsequently tested in the same closed compartment with no shock, normal rats showed an increased tendency to freeze. They also showed an increased tendency to actively avoid the compartment when given access to an adjacent neutral compartment for the first time. Amygdala inactivation with bilateral muscimol injections before training attenuated freezing and eliminated avoidance during the test. Rats trained in a normal state and given intra-amygdala muscimol injections before the test did not freeze or avoid the shock-paired compartment. This pattern of effects suggests that amygdala inactivation during training impaired acquisition of a conditioned response (CR) due either to inactivation of a neural substrate essential for its storage or to elimination of a memory modulation effect that facilitates its storage in some other brain region(s). The elimination of both freezing and active avoidance by amygdala inactivation during testing suggests that neither of these behaviors is the CR. The possibility that the CR is a set of internal responses that produces both freezing and avoidance as well as other behavioral effects is discussed.
\end{abstract}

In aversive conditioning procedures, neutral cues such as those that comprise an experimental context (conditioned stimuli; CS) are paired with an aversive event such as footshock (unconditioned stimulus; US). Usually only a few CS-US pairings are required to produce a variety of changes in behavior upon subsequent exposure to the CS alone (Fanselow 1984; Davis 1997, 2000; LeDoux 1998, 2000a; Fendt and Fanselow 1999). The present study compared two such behaviors elicited by cues that make up the context in which an aversive US (footshock) has occurred; reductions in activity (including a measure of freezing) and active avoidance of the context, or place where the US was experienced. The function of the amygdala in producing these behaviors was studied.

Freezing, defined as a cessation of motor activity including whisker and nose movements (Bolles and Collier 1976) or sitting rigidly motionless (Bindra and Anchel 1963) except for movement necessitated by respiration (Fanselow 1980), is elevated during exposure to an aversive contextual CS (Brown et al. 1951; Blanchard and Blanchard 1969; McAllister and McAllister 1971; Bolles and Riley 1973; Bouton and Bolles 1980; Fanselow 1984; LeDoux 1996, 2000b).

Pretraining electrolytic lesions of the amygdala complex attenuate elevated freezing during exposure to a shock-paired compartment (Phillips and LeDoux 1992), as do lesions restricted to the medial (MeA; Blanchard and Blanchard 1972; Holahan and White 2002), the central (CeA), or basolateral (BLA) amygdala regions (Kim et al. 1993; Amorapanth et al. 2000; Nader et al. 2001; Holahan and White 2002). Pretraining (Maren, 1998, 1999; Vazdarjanova and McGaugh, 1998; Cahill et al. 2000) or posttraining (Lee et al. 1996; Maren et al. 1996a; Maren 1998) NMDA lesions of the BLA as well as pretraining NMDA lesions of the lateral amygdala (LA) or CeA (Goosens and Maren 2001) also block freezing during exposure to a contextual CS.

\section{'Corresponding author.}

2Present address: Department of Psychology, Northwestern University, Evanston, IL 60208, USA.

E-MAIL m-holahan@northwestern.edu; FAX (847) 491-7859.

Article published online ahead of print. Article and publication date are at http://www.learnmem.org/cgi/doi/10.1101/lm.64704.
Freezing elicited by exposure to shock-paired cues is also attenuated by pretraining (Fanselow and Kim 1994) or pretesting (Maren et al. 1996b; Fendt 2001; Lee et al. 2001) intra-amygdala injections of the NMDA antagonist AP5. Lidocaine injected into the amygdala (Helmstetter 1992) completely eliminated freezing when given before testing but was less effective when administered prior to training. The $\mathrm{GABA}_{\mathrm{A}}$ agonist muscimol disrupted freezing when injected into the BLA region before training or testing (Helmstetter and Bellgowan 1994; Muller et al. 1997; Wilensky et al. 1999). Studies that have reversibly interfered with intracellular mechanisms in the amygdala (Bailey et al. 1999; Schafe and LeDoux, 2000; Schafe et al. 2000; Bauer et al. 2002; Lamprecht et al. 2002) have also reported blockade of freezing.

Two general hypotheses have been proposed to explain the deficits in freezing produced by impaired amygdala function. One suggests that the amygdala is part of a neural system that stores information required for aversive CSs to potentiate freezing (Fanselow and LeDoux 1999; Fendt and Fanselow 1999; Maren 1999, 2001; LeDoux 2000a; Fanselow and Gale 2003). The other argues that the elimination of freezing with amygdala lesions or inactivation is due to an inability to express the behavior rather than an effect on learning (Cahill et al. 1999, 2000; Vazdarjanova et al. 2001) and animals may be able to express the learned information in other ways.

Place avoidance can also be produced during exposure to an aversive contextual CS (Mowrer and Lamoreaux 1946; Mowrer 1947; Miller 1948). In this case, rats that have been shocked while confined in a compartment and subsequently allowed to move freely (with no shock) between that compartment and a neutral one, spend less time in the shocked than in the neutral compartment (Miller 1948; Goldstein 1960; Campbell and Campbell 1962; McAllister and McAllister 1962; Blanchard and Blanchard 1968, 1970a,b; Kumar 1970; Selden et al. 1991; Vazdarjanova and McGaugh 1998; Antoniadis and McDonald 1999; Holahan and White 2002).

Avoidance of a shock-conditioned context is impaired by both electrolytic (Gaston and Freed 1969) and neurotoxic (Jellestad and Cabrera 1986; Antoniadis and McDonald 2000) lesions of the amygdala complex. Lesions restricted to specific 
amygdala regions have produced less consistent results. Lesions of the LA or BLA blocked active avoidance of a tone-paired shock (Killcross, et al. 1997; Amorapanth et al. 2000) while neither electrolytic (Holahan and White 2002), quinolinic (Selden et al. 1991), ibotenic (Jellestad and Cabrera 1986; Ambrogi Lorenzini et al. 1991), nor NMDA (Vazdarjanova and McGaugh 1998) lesions of the BLA disrupted place avoidance. Electrolytic lesions of the CeA impaired active avoidance of shock-conditioned cues in some reports (Poremba and Gabriel 1997; Smith et al. 2001; Holahan and White 2002) but not others (Killcross et al. 1997; Amorapanth et al. 2000).

Freezing involves the suppression of activity while place avoidance requires the initiation of activity in order to move from one place to another. It is obvious that the two behaviors cannot occur at the same time, and it has been shown that elevations in freezing interfere with expression of active avoidance (Anisman and Waller 1972, 1973; Anisman 1973). Although they represent opposing behavioral tendencies, freezing and place avoidance are both elicited by aversive contextual CSs. This raises questions about whether either of these observable behaviors can be a conditioned response (CR) that is directly elicited by exposure to an aversive CS, or whether they are elicited indirectly by the CS as the result of some internal CR often referred to as "fear" (Fanselow 1984; Davis 1992, 1997; LeDoux 2000a; Maren 2001) or as a "conditioned affective state" (Mowrer 1947; Miller 1948; Brown and Jacobs 1949; White and McDonald 2002) that affects them both. The fact that both freezing and place avoidance are affected by impaired amygdala function raises additional questions about the relationship of the normal function of the amygdala to the hypothesized internal CRs and the observable behaviors.

In the present experiment rats were shocked in a closed compartment then tested without shock in the same closed compartment. An automated measure of freezing (Inactivity/ Freezing, or IF) that correlates highly with observed freezing (see Materials and Methods for details) was made in these conditions. The rats were also tested with the door to an adjacent neutral compartment open for the first time. Avoidance of the shock compartment and movement between the two compartments (crossovers) were measured. The effects of intra-amygdala muscimol injections given before training or before testing on the expression of these behaviors were examined. The experiment permitted a direct comparison of the effects of amygdala inactivation on two competing behavioral tendencies-suppression of activity (freezing) and initiation of activity (place avoidance). Together with the crossover measure, the findings constrain hypotheses concerning (1) the function of the amygdala in aversive conditioning and (2) the nature of the conditioned response in aversive conditioning.

\section{RESULTS}

\section{Muscimol Injections}

Permanently implanted guide cannulae were aimed bilaterally at the amygdala complex. Figure 1 shows representative brain sections from rats that received pretraining or pretesting saline or muscimol injections using injection cannulas inserted into the brain through the guides. The injector tips were located slightly dorsal to or within the CeA. No substantial damage to any part of the amygdala was produced by the injectors and there were no systematic differences among the groups in the injection sites, which ranged from $1.8-3.1 \mathrm{~mm}$ posterior to bregma.

\section{C-Fos Assessment}

Muscimol suppresses neural activity by activating inhibitory GABA receptors located on the cell bodies of neurons (Steele and Mauk 1999; Edeline et al. 2002). To estimate the extent of amyg-

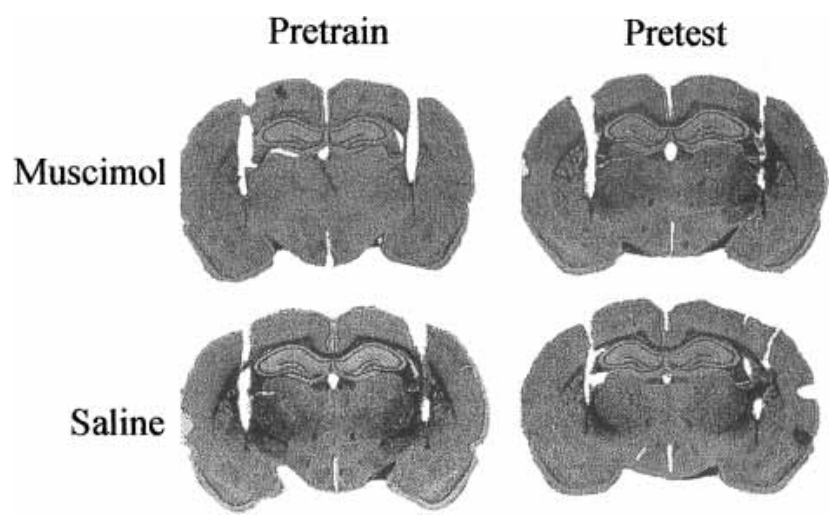

Figure 1 Representative sections with cannula tracks. Sections were randomly taken from rats injected with saline or muscimol before context-shock pairings (pretrain) or before testing (pretest). Injector tips were within the central amygdala nucleus or immediately dorsal to it.

dala inactivation produced by the muscimol injections in the present experiment, four rats that received saline and four that received muscimol injections before the closed-door test in the shock-paired compartment were sacrificed 90 min after the test and their brains were processed for c-Fos protein immunohistochemistry.

An adjacent brain section caudal to the injection site in each rat, ranging from $2.1-2.7 \mathrm{~mm}$ posterior to bregma, was selected for analysis. Representative sections are shown in Figure 2. The section from the rat injected with muscimol has a zone of c-Fos suppression that included all amygdala regions (LA/BLA, CeA, and $\mathrm{MeA}$ ) and the adjacent cortex ventral to the amygdala. It was not possible to determine whether the muscimol spread dorsally because, as previously reported (Wang and Redgrave 1997), implantation of guide cannulas and either muscimol and saline injections produce dense c-Fos labeling around the guide and injector tracks. Some of the injectors were located within the boundaries of the CeA in both saline and muscimol injected rats. Consequently, high levels of c-Fos labeling were found, possibly due to an expression artifact produced by the injector tip.

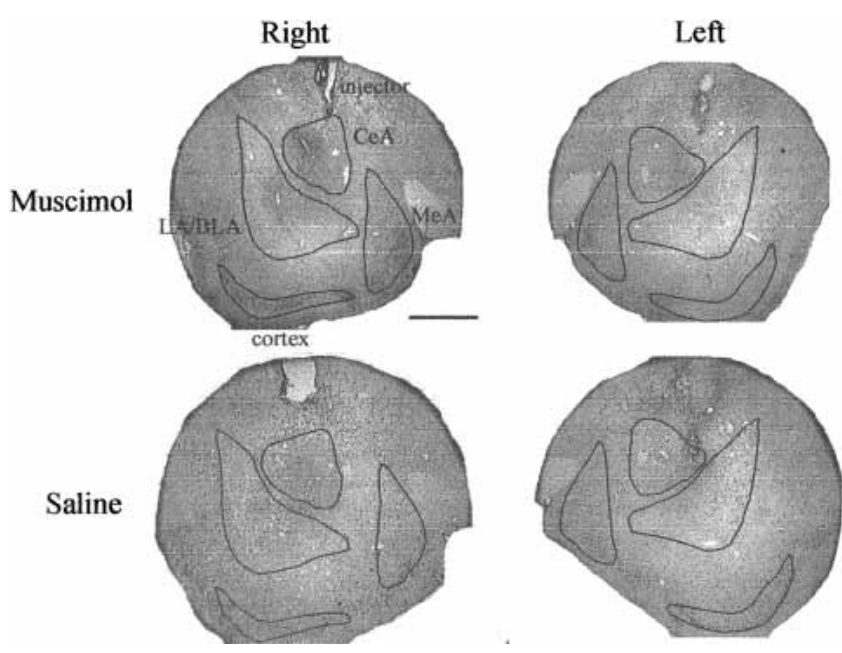

Figure 2 Sections of the amygdala complex stained for c-Fos protein expression. Right and left hemispheres are shown from rats injected with muscimol or saline before the closed-door test. c-Fos expression is visible around the injector tip in both rats and throughout the amygdala in the saline-injected rat, but decreases rapidly with distance from the tip in the muscimol-injected rat. LA/BLA, lateral/basolateral amygdala; CeA, central amygdala; MeA, medial amygdala. Bar, $1 \mathrm{~mm}$. 
C-Fos labeled cells within the left and right LA/BLA, CeA, $\mathrm{MeA}$ and in the cortex ventral to the amygdala were counted in all eight rats. Taking each of the four regions of interest in each hemisphere separately, the count for each of the four rats that received muscimol and each of the four that received saline was expressed as a percentage of the mean of the counts for the four rats that received saline. The means of these percentage scores are shown in Figure 3. Intra-amygdala muscimol injections reduced c-Fos labeling in both the left and right LA/BLA and MeA, and in the adjacent cortex ventral to the amygdala. There was a less pronounced reduction in the CeA, possibly due to the artifact produced by the injector (Wang and Redgrave 1997). These data were analyzed with a three-way ANOVA (Group $\times$ Amygdala Region $\times$ Hemisphere) with repeated measures on the last two factors. There was a significant main effect of group $(\mathrm{F}(1,6)=11.40, P<0.02)$ but no significant effects of region $(\mathrm{F}(1,6)<1.0)$ or hemisphere $(\mathrm{F}(1,6)=3.69, P=0.1)$ and no significant interactions. This analysis suggests that neural activity in most of the amygdala was affected by the muscimol injections and that the injections may have also affected neurons in the adjacent cortex and possibly other brain regions that were not examined. These findings preclude attributing the behavioral effects of the muscimol injections to any specific amygdala subregion.

In a previous report (Wang and Redgrave 1997), $0.5 \mu$ of a $50 \mathrm{ng}$ dose of muscimol injected into the superior colliculus inactivated neurons within a radius of $\sim 0.5 \mathrm{~mm}$ from the injection
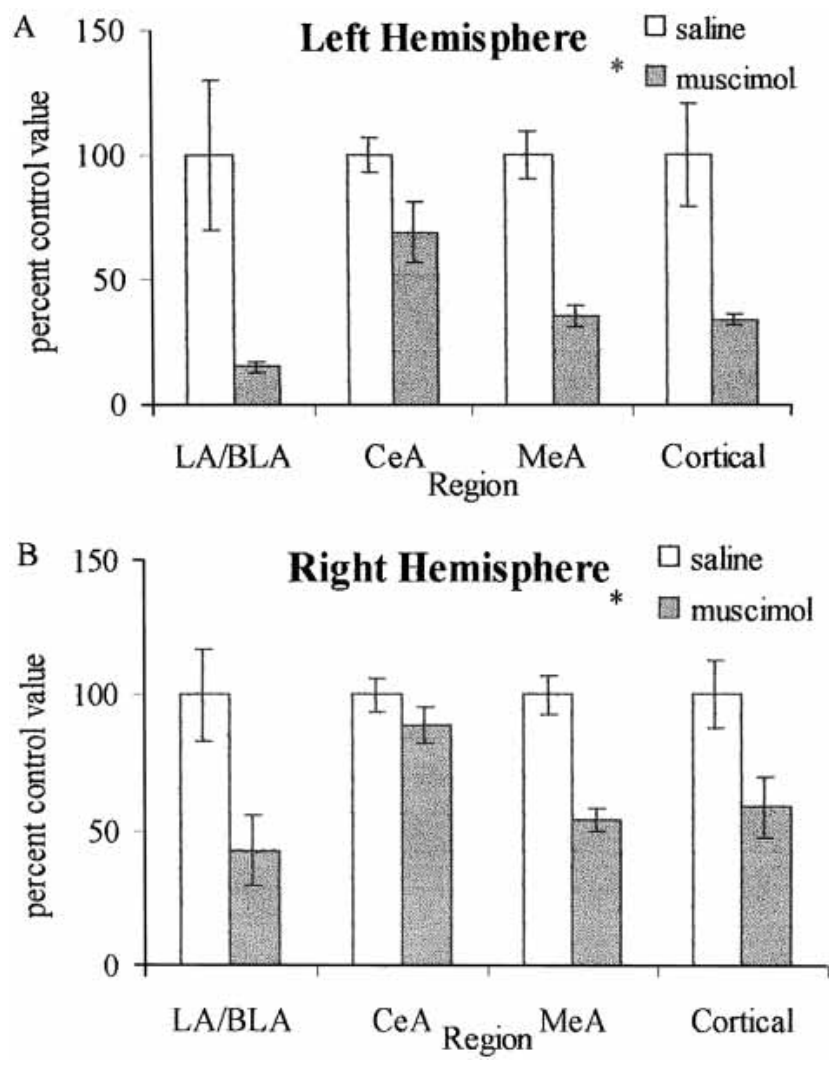

Figure 3 Quantitative analysis of c-Fos data. Data are expressed as mean \pm SEM. (A) Left hemisphere. (B) Right hemisphere. C-Fos expression was reduced in all regions examined $(\mathrm{LA} / \mathrm{BLA}$, lateral/basolateral amygdala; CeA, central amygdala; MeA, medial amygdala; Cortical, cortical amygdala and piriform cortex). The relatively small difference between the saline and muscimol injected rats in the CeA is most likely due to the elevation in c-Fos expression produced by the injector tip. ${ }^{*} P<0.05$ main effect of group (saline vs. muscimol).
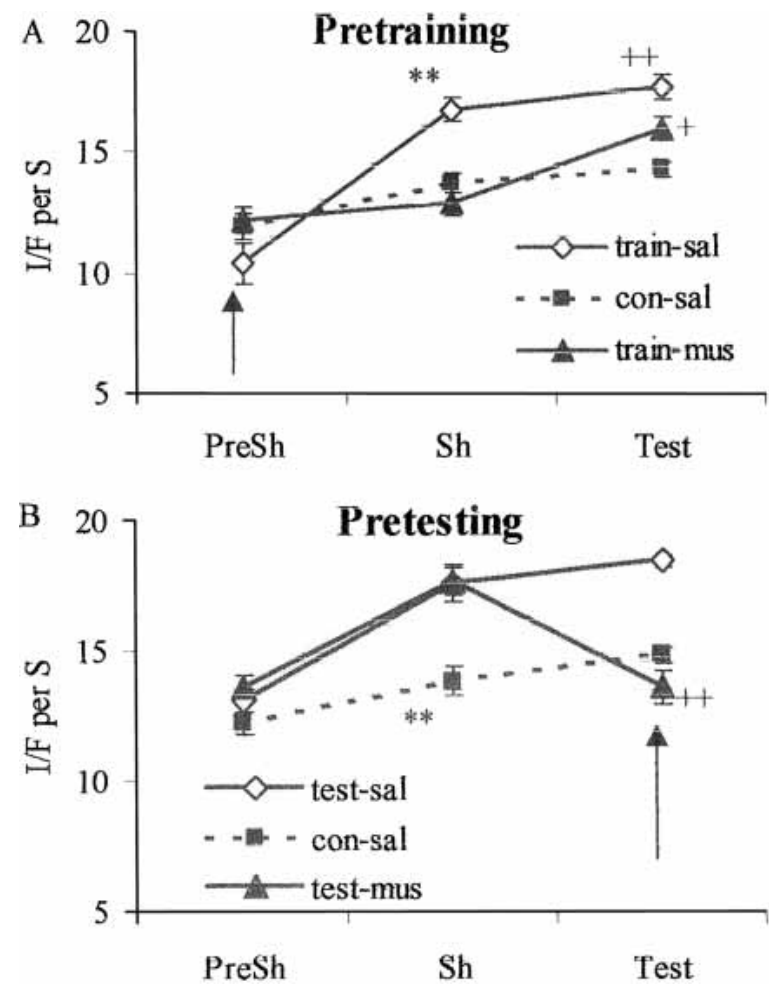

Figure 4 Data collected during the 2-min preshock phase (PreSh) and 4-min shock phase (Sh) on the training day and during the 6-min closeddoor test (Test). (A). Pretraining: rats were injected with saline (train-sal) or muscimol (train-mus) and shocked or saline (con-sal) and not shocked. ${ }^{* * P}<0.01$ vs. con-sal and train-mus during Sh phase. $++P<0.01$ vs. con-sal during Test. $+P<0.05$ vs. train-sal and con-sal during Test. (B). Pretesting: rats were shocked and injected with saline (test-sal) or muscimol (test-mus) or not shocked and injected with saline (con-sal) before testing. ${ }^{* *} P<0.01$ vs. test-sal and test-mus during Sh phase. $++P<0.01$ vs. test-sal during Test. Arrows indicate when the injections were given

site. Martin (1991) reported that $1000 \mathrm{ng}$ of radioactively labeled muscimol injected in a volume of $1.0 \mu \mathrm{l}$ spread $1.8 \mathrm{~mm}$ from the injection site. In the present study, $50 \mathrm{ng}$ of muscimol injected in a volume of $1.0 \mu \mathrm{l}$ reduced c-Fos activation within a radius of at least $2.0 \mathrm{~mm}$ and possibly more. These results lead to three conclusions: (1) The diffusion pattern of the drug may depend on the brain region into which it is injected; (2) brain regions may differ in their sensitivity to muscimol; (3) the area in which radioactivity can be detected may differ from the area in which the effects of muscimol are detected by the c-Fos method.

\section{Training and Closed-Door Test}

Data for the rats given intra-amygdala muscimol injections before shock training are shown in Figure 4A. The data were analyzed with a two-way ANOVA with groups as a between factor and phase as a repeated measure, followed by Fisher's LSD tests to localize significant effects. For the pretraining groups, there were significant main effects of group $(\mathrm{F}(2,17)=6.42, P<0.01)$ and phase $(\mathrm{F}(2,4)=55.94, P<0.0001)$ and a significant interaction $(\mathrm{F}(4,34)=10.39, P<0.0001)$. There were no significant differences among the groups during the 2 min prior to shock application. During the shock phase, group train-sal (injected with saline and shocked) had a higher I/F score than group con-sal (injected with saline and not shocked; $\mathrm{t}(12)=4.97, P<0.001$ ), indicating that shock contributed to elevated freezing during the session. The I/F score for group train-mus (injected with muscimol and shocked) was significantly lower than that of group 
train-sal $(\mathrm{t}(11)=5.73, P<0.001)$ and did not differ from that of group con-sal $(\mathrm{t}[12]=1.16, P=0.22)$. Thus, muscimol eliminated the increased I/F produced by shock during the training session.

During the test, when these rats received neither injections nor shock, group train-sal had a higher mean I/F score than group con-sal $(\mathrm{t}[12]=4.71, P<0.01)$, suggesting the occurrence of conditioned freezing. The I/F score for group train-mus was significantly lower than that for group train sal $(\mathrm{t}[12]=2.43$, $P<0.05)$ but significantly higher than the score for group con-sal $(\mathrm{t}[12]=2.27, P<0.05)$. Group train-mus also showed a significant increase in $\mathrm{I} / \mathrm{F}$ from the shock phase to the test phase $(\mathrm{t}[12]=4.20, P<0.01)$. Thus, pretraining muscimol attenuated conditioned freezing when the rats were tested without shock or muscimol.

For the rats injected before testing (Fig. 4B), there were significant main effects of group $(\mathrm{F}[2,14]=12.10, P<0.001)$ and phase $(\mathrm{F}[2,4]=39.90, P<0.0001)$ and a significant interaction $(\mathrm{F}[4,28]=12.67, P<0.0001)$. There were no significant differences among the groups during the 2 min prior to shock application. During the shock phase when no injections were given, $\mathrm{I} / \mathrm{F}$ was elevated in groups test-sal (shocked; $\mathrm{t}[10]=3.79, P<0.01$ ) and test-mus (shocked; $\mathrm{t}[9]=4.43, P<0.01$ ) compared to group con-sal (not shocked). During the test phase, I/F in group testmus (injected with muscimol) was significantly lower than I/F in group test-sal (injected with saline; $\mathrm{t}[9]=5.90, P<0.001$ ), and did not differ significantly from $\mathrm{I} / \mathrm{F}$ in group con-sal (injected with saline; $\mathrm{t}[9]=1.44, P=0.18$ ). For group test-mus, mean $\mathrm{I} / \mathrm{F}$ during the test was not significantly different from its value during the preshock period $(\mathrm{t}[8]=0.10, P=0.94)$ and decreased significantly from its value during the shock phase $(\mathrm{t}[8]=5.60$, $P<0.01)$. Thus, pretesting muscimol eliminated (conditioned) freezing observed in shocked control rats.

Intra-amygdala muscimol injections normalized I/F during training and testing when given prior to either of these sessions. Previous studies (Helmstetter and Bellgowan 1994; Muller et al. 1997; Wilensky et al. 1999, 2000) have reported similar effects of amygdala inactivation on freezing. These findings are consistent with the hypothesis that impairments of amygdala function produce a deficit in the ability to freeze (Cahill et al. 2000; Vazdarjanova et al. 2001). However, the basis for this deficit is unclear.

I/F was attenuated but not eliminated during a drug-free test in rats that were shocked $40 \mathrm{~min}$ after receiving muscimol injections (train-mus). Electrophysiological and autoradiographic measures show that spontaneous neural activity in the area surrounding the injection site is reduced by $80 \% 2 \mathrm{~min}$ after an injection of $1 \mu \mathrm{g} / \mu \mathrm{l}$ of muscimol (Edeline et al. 2002). Maximum suppression is attained 10 (Martin 1991) to 25 (Edeline et al. 2002) min after injection and lasts for about $2 \mathrm{~h}$ (Martin 1991; Edeline et al. 2002) and possibly longer. These findings suggest that in the present study the drug was probably at maximum effectiveness in the pretraining group. This makes it unlikely that the partial attenuation of $\mathrm{I} / \mathrm{F}$ during testing in this group was due to incomplete blockade of amygdala function during training. The data also suggest that muscimol was highly effective in the pretesting group when it was injected 15 min before testing.

Because the rats injected before training were in a normal state during the test, the attenuation of I/F cannot be attributed to an impaired ability to freeze. The presence of freezing in the shocked groups that did not receive muscimol injections (trainsal and test-sal) implies that some kind of information about the environment in which the shock was experienced, possibly about the relationship between the US and the CS (LeDoux 2000a; Fanselow and Gale 2003; Maren 2003), is normally stored somewhere in the brain. The attenuation of freezing by musci- mol injected prior to training (train-mus) suggests that this storage process was at least partially impaired in some way. Possible reasons for this impairment will be considered in the Discussion section.

\section{Open-Door Test}

On the day following the closed-door test, rats in the pretraining group were placed into the compartment in which they had been shocked with the door to an adjacent neutral compartment open for the first time. Another group of rats that were trained in a normal state received this test $48 \mathrm{~h}$ after shock training. These rats received intra-amygdala muscimol or saline injections before the open-door test. Time spent in the shock-paired and neutral compartments (place avoidance) and movement between the two compartments (crossovers) were measured for the period starting after the rat crossed into the neutral compartment for the first time (see Materials and Methods for details).

\section{Crossovers}

As shown in Figure 5A, the crossover rates for shocked rats injected with muscimol before training (train-mus) were higher than those for shocked rats injected with saline (train-sal) and comparable to the rates for nonshocked rats injected with saline (con-sal). There was a significant group effect $(\mathrm{F}[2,18]=4.89$, $P<0.05)$ and significant differences between groups train-sal and con-sal $(\mathrm{t}[12]=3.48, P<0.01)$ and between groups train-sal and train-mus $(\mathrm{t}[12]=2.08, P<0.05)$. The crossover rates for groups con-sal and train-mus were not significantly different $(\mathrm{t}[12]=0.76, P=0.46)$. For the groups injected with muscimol before open door testing (Fig. 5B) there was a significant group effect $(\mathrm{F}[2,17]=21.97, P<0.001)$ and significant differences between groups test-sal and con-sal $(\mathrm{t}[11]=2.82, P<0.01)$ and between groups test-sal and test-mus $(\mathrm{t}[12]=6.55, P<0.01)$. The crossover rates for groups con-sal and test-mus were also significantly different $(\mathrm{t}[11]=3.47, P<0.01)$.
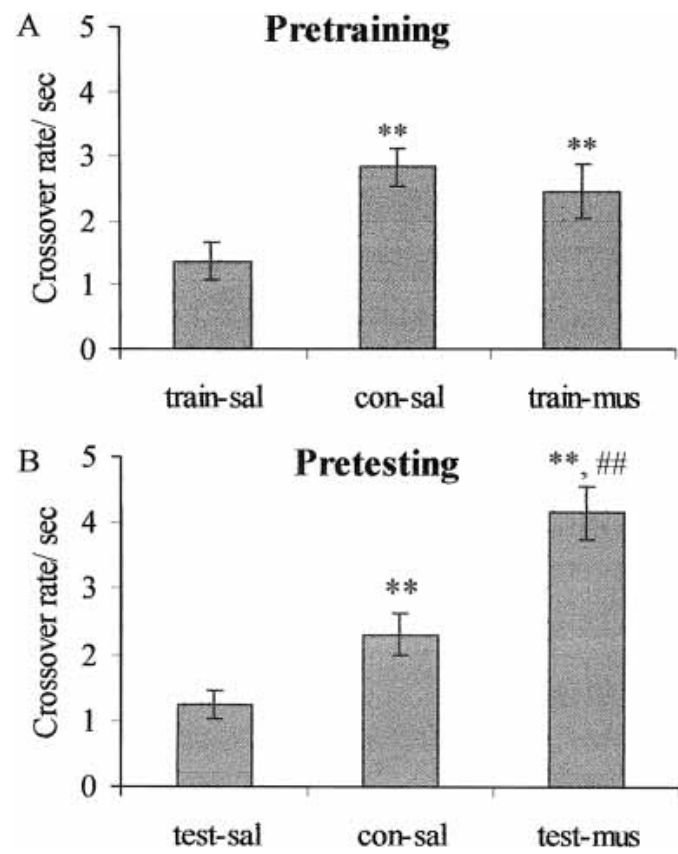

Figure 5 Open-door test. Crossover rates are the number of times a rat moved between the two compartments minus one divided by the total session time minus the time of the first bout in the paired compartment. Abbreviations as in Figure 4. $(A)$. Pretraining. ${ }^{* *} P<0.01$ vs. train-sal. $(B)$ Pretesting. ${ }^{* *} P<0.01$ vs. test-sal, $\# \# P<0.01$ vs. con-sal. 
The reduced crossover rates in the rats that were shocked and injected with saline during the training (train-sal) or testing (test-sal) sessions, compared with the rats that were not shocked and injected with saline (con-sal), are consistent with previous evidence that exposure to both unconditioned and conditioned aversive cues reduces activity levels (Blanchard and Blanchard 1969; Brener and Goesling 1970; Kumar 1970). Both pretraining (train-mus) and pretesting (test-mus) muscimol injections reversed these reductions, a finding that is consistent with the suggestion that amygdala inactivation may affect the ability to suppress movement, impairing the ability to freeze.

The suppressed crossover rates in group train-sal, compared to those in group con-sal, suggest the existence of conditioned suppression of movement. The elimination of this suppression by pretraining muscimol in group train-mus cannot be attributed to an inability to suppress movement because the rats in these groups were tested in a normal state. Accordingly, this effect of muscimol may be best attributed to an effect on acquisition of the memory that produced the conditioned suppression. The nature of this effect will be addressed in the Discussion.

During the open-door test, crossovers were elevated in the test-mus group compared to the con-sal group suggesting the possibility that intra-amygdala muscimol injections elevated activity to a supernormal level. Such an effect could interfere with the ability to perform specific behaviors such as freezing, distorting the inference of an underlying process from changes in those behaviors (McAllister and McAllister 1971). However, there are several reasons to doubt that the increased crossovers in the present experiment were an instance of a general effect of amygdala inactivation. First, the fact that there was no difference in I/F between groups test-mus and con-sal during the closed-door test is inconsistent with the existence of such an effect. Second, we have previously reported (Holahan and White 2001) that nonshocked rats injected with muscimol or saline have similar activity levels (muscimol: $2.99 \pm 0.30$ crossovers/sec; saline: $2.49 \pm 0.33 ; \mathrm{t}[8]=1.0, P=0.35)$ and latencies to exit their "paired" compartment (muscimol $3.65 \pm 0.83 \mathrm{sec}$; saline: $5.73 \pm 1.51 ; \mathrm{t}[8]=1.5, P=0.26)$ in the same apparatus as was used in the present experiments. Third, others have reported that amygdala lesions do not produce elevations in activity levels during exposure to aversive cues (Goldstein 1968; Decker et al. 1995; Maren 1998; Fanselow and Gale 2003).

\section{Place Avoidance}

As shown in Figure 6, both pretraining and pretesting muscimol injections eliminated the place avoidance exhibited by the shocked, saline-injected groups. For the pretraining groups (Fig. $6 \mathrm{~A})$, there was a significant group effect $(\mathrm{F}[2,18]=15.14$, $P<0.001)$ and significant differences between groups train-sal and con-sal $(\mathrm{t}[12]=5.16, P<0.01)$ and between groups train-sal and train-mus $(\mathrm{t}[12]=4.23, P<0.01)$. The avoidance ratios for groups con-sal and train-mus were not significantly different $(\mathrm{t}[12]=0.93, P=0.38]$. For the pretesting groups (Fig. 6B), there was a significant group effect $(\mathrm{F}[2,17]=13.64, P<0.001)$ and significant differences between groups test-sal and con-sal $(\mathrm{t}[11]=5.03, P<0.01)$ and between groups test-sal and test-mus $(\mathrm{t}[12]=3.66, P<0.01)$. The avoidance ratios for groups con-sal and test-mus $[\mathrm{t}(11)=1.51, P=0.14]$ were not significantly different.

The rats in the pretraining groups were exposed to the conditioned cues with the door closed before the open door test, raising the possibility that elimination of the place avoidance behavior was due to some form of extinction. However, the avoidance ratio for the test-sal subgroup that was given only the open door test was 0.57 , while the ratio for the train-sal group on its second exposure to the conditioned cues was 0.62 . If extinc-
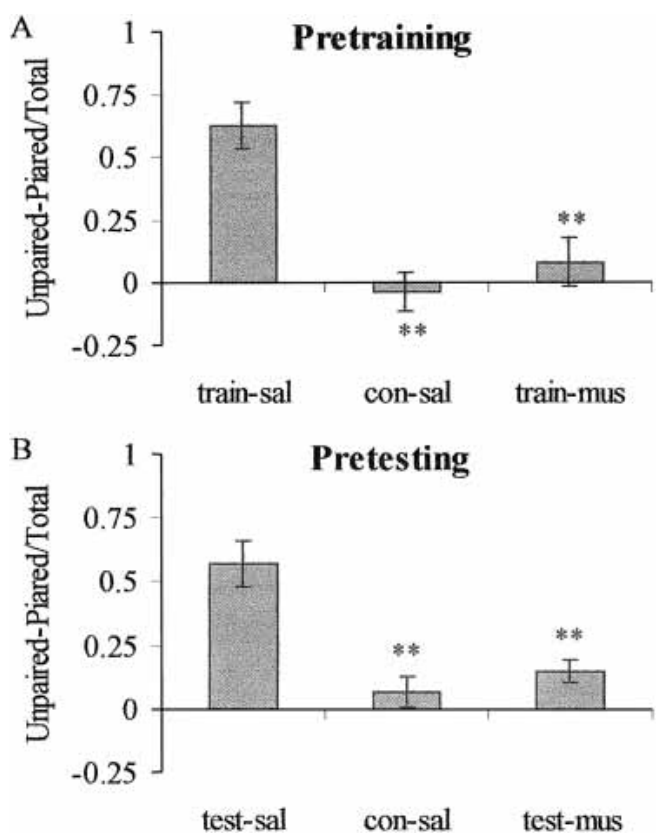

Figure 6 Open-door test. Avoidance ratios were calculated as the time spent in the unpaired compartment minus the time spent in the paired compartment divided by the total time. Abbreviations as in Figure 4. $(A)$. Pretraining. ${ }^{* *} P<0.01$ vs. train-sal. $(B)$. Pretesting. ${ }^{* \star} P<0.01$ vs. test-sal.

tion had occurred, the train-sal group's ratio would have been lower than the test-sal group's ratio.

The rats that were trained in a normal state and tested after injections of muscimol failed to avoid the shock-paired compartment. Although their crossover rates were higher than those for the saline control rats, there is no conclusive evidence that activity levels affect conditioned avoidance (Holahan and White 2003) and clear evidence that activity levels do not affect the expression of conditioned preferences (Hiroi and White 1991; White and McDonald 1993).

The rats injected prior to closed-door training exhibited avoidance ratios comparable to non-shocked rats and failed to avoid the paired compartment even though their amygdalas were normal during the test. Accordingly, these behaviors cannot be attributed to any immediate effect of impaired amygdala function. Rather, such effects must have been due to a failure to acquire some form of information about the paired compartment. This could not have included any information about the avoidance behavior, since there had been no previous opportunity to perform that behavior or to learn about the escape route to the neutral compartment.

There are at least two previous reports that lesions of the amygdala had no effect on avoidance. Selden et al. (1991) measured avoidance in a preference apparatus similar to the one used in the present experiments. During the test, shocked rats spent approximately 160 and $180 \mathrm{sec}$ (depending on the training parameters) of a 300-sec test in the safe compartment (Selden et al. 1991, Fig. 4, p. 343). Applying the avoidance ratio calculation used in the present experiment to these values gives ratios of 0.08 and 0.20 . These contrast with values in the range of 0.5-0.6 in the present experiment and suggest that the lesions in Selden et al. may have failed to eliminate avoidance because there was little or no avoidance to eliminate in control animals. This may have been because the rats in Selden et al. were given relatively mild footshock and exposed to the apparatus with no shock after training, which may have partially extinguished the aversive CR. 
It is also possible that the difference between the two experiments is due to the fact that Selden et al. made permanent lesions with quinolinic acid while the effects in the present experiment were produced by temporary inactivation with muscimol.

Vazdarjanova and McGaugh (1998) shocked rats in one arm of a Y-Maze and subsequently placed the rats into one of the no-shock arms and observed their behavior for $8 \mathrm{~min}$ with all arms open in the absence of shock. Sham-lesioned, shocked rats spent almost no time in the shocked arm; basolateral lesioned, shocked rats entered the shock arm after about half the session but still exhibited strong avoidance compared to a lesioned, noshock control group. There are two major differences in procedure between this study and the present one. First, Vazdarjanova and McGaugh used longer duration footshocks than were used in the present experiment. Second, Vazdarjanova and McGaugh placed their rats in a no-shock arm at the start of the testing session, whereas the rats in the present experiment were started in the shock compartment. This might have allowed more extinction in the present study. Both of these factors could account for the partial elimination of avoidance reported by Vazdarjanova and McGaugh compared to the complete elimination of this behavior in the present study. It should also be noted that Vazdarjanova and McGaugh made neurotoxic lesions of the amygdala whereas temporary inactivation with muscimol was used in the present experiment.

\section{DISCUSSION}

Intra-amygdala muscimol injections completely eliminated $\mathrm{I} / \mathrm{F}$ (equivalent to freezing) observed in normal rats during shock training. Compared to saline-injected rats, rats injected with muscimol during training subsequently froze less and failed to avoid the shock-paired cues when tested without shock. Rats that were given intra-amygdala muscimol injections before open- and closed-door testing also froze less and failed to avoid the shockpaired cues. These findings have implications for understanding the function of the amygdala, and for identifying the conditioned response in aversive conditioning situations.

\section{Amygdala: Memory and Modulation}

The effects of amygdala inactivation during training on all three of the conditioned aversive behaviors measured in this experiment suggest that their occurrence in normal rats is due to a mnemonic process of some kind.

\section{Freezing}

Increased I/F during training and closed-door testing was eliminated when muscimol was given immediately before these sessions. Previous reports (Helmstetter and Bellgowan 1994; Muller et al. 1997) have also found that pretraining or pretesting intraamygdala muscimol injections blocked freezing in the presence of an aversive CS. These effects could be due to a performance deficit (Cahill et al. 1999, 2000, 2001) or to an effect on an underlying mnemonic process (Fanselow and LeDoux 1999; Schafe et al. 2001; Fanselow and Gale 2003; Maren 2003).

As already discussed, the reduced freezing observed in rats trained with inactivated amygdalas and tested in a normal state cannot be attributed to a performance deficit but is consistent with the hypothesis that amygdala inactivation during training prevented the acquisition of a Pavlovian conditioned response.

During the training session the elimination of freezing by amygdala inactivation could have been caused by a performance deficit but there is also evidence that supports the alternative interpretation. There are a number of demonstrations that little or no freezing occurs after a shock-training session if the conditioned cues are eliminated (Blanchard and Blanchard 1969;
Bolles and Collier 1976; Fanselow 1980; Holahan and White 2004b). These findings have led to the suggestion that freezing during a training session is elicited by the conditioned cues, as it is during a test session when no shocks are delivered (Bolles and Collier 1976; Fanselow 1980). If this is the case, the elimination of increased I/F by inactivation of the amygdala during training could be explained as a failure to acquire (and retrieve) an aversive Pavlovian association.

The finding that pretesting injections of muscimol attenuated conditioned freezing during the closed-door test is consistent with both the performance deficit hypothesis and the possibility that it resulted in a failure to retrieve an aversive Pavlovian association.

\section{Crossovers}

Intra-amygdala muscimol injected during either the training or testing trials also eliminated the suppression of activity measured by crossovers during the open door test. The effect of pretesting muscimol could have been due to a failure to suppress activity. However, the normalization of the crossover rates by pretraining muscimol could not have been due to such a process because the amygdala was in a normal state when the rats were tested. Therefore, this effect is best explained as a failure to acquire a Pavlovian association during training or to retrieve it during testing with an inactivated amygdala. According to this hypothesis, the aversive $\mathrm{CR}$ produced by this association in normal rats suppresses activity.

\section{Avoidance}

Rats that received intra-amygdala muscimol before either training or testing failed to exhibit place avoidance. These effects of amygdala inactivation cannot be attributed to a failure to inhibit movement because they occurred in the presence of both reduced and elevated activity levels (compare Figs. 5 and 6), or to a failure to acquire any specific behavior because there was no opportunity to learn the avoidance response. The effects can be attributed to the failure of acquisition (pretraining muscimol) or expression (pretesting muscimol) of some form of learned information, possibly an aversive Pavlovian association that produced the avoidance behavior.

\section{Mnemonic Function}

The present findings lead to the conclusion that some mnemonic process was affected by amygdala inactivation. At least two hypotheses concerning this process are possible. First, the amygdala may be part of a neural system required for storage of Pavlovian associations that produce conditioned aversive responses (Fanselow and LeDoux 1999, LeDoux 2000a; Maren 2001, 2003; Fanselow and Gale 2003). This hypothesis explains the effects of amygdala inactivation during training as a failure to acquire such an association and the effects of inactivation during testing as a failure to express it, in both cases due to impaired function of the neural substrate that stores the information required to produce the conditioned responses.

Second, there is considerable evidence that the amygdala mediates a memory modulation response that facilitates storage of representations in other parts of the brain (Ammassari-Teule et al. 1991; Cahill and McGaugh 1991; Packard et al. 1994; Roozendaal and McGaugh 1996; Packard and Teather 1998; Cahill et al. 1999, 2001; Packard and Cahill 2001; Holahan and White 2002). There is also evidence implicating brain areas other than the amygdala in aversive conditioning, including dorsal striatum (Viaud and White 1989; White and Salinas 2003) and cerebellum (Sacchetti et al. 2002). In the present study, impairing amygdala function during training would have eliminated or attenuated this modulation response, preventing or weakening 
storage of associations that normally produce observed aversive behaviors. This hypothesis implies that the amygdala is not part of the neural substrate that stores the associations.

On its own, this hypothesis does not explain the observation that amygdala inactivation on the test trials prevented expression of all behaviors measured. Because the modulation hypothesis implies that the amygdala is not part of a memory storage circuit, the data mean that an intact amygdala is required for retrieval and or expression of aversive associations stored elsewhere. This would require postulating a facilitatory signal of some kind that originates in the amygdala, or that the output of extra-amygdala storage system(s) is routed through the amygdala, which controls its behavioral output. The present data neither support nor eliminate these possibilities.

In summary, the modulation hypothesis explains the effects of inactivation during training as a failure of modulation and the effects of inactivation during testing as a failure to produce the behaviors. Both parts of this explanation must be true to explain all of the findings.

\section{Identification of the UR/CR}

The present findings and others discussed show that manipulations of the amygdala alter rats' responses to the presence of unconditioned and conditioned aversive stimuli. One way to approach the question of how the amygdala produces these changes is to ask about the output of the amygdala, about the nature of the URs and CRs it produces.

One description of these responses is suggested by the observation that lesions to specific parts of the amygdala affect specific behaviors. It has been reported that lesions of the BLA but not CeA block active avoidance of shock-paired cues but not conditioned freezing (or suppression; Killcross et al. 1997; Amorapanth et al. 2000). This has lead to the suggestion that parallel systems in the amygdala might control different fearrelated CRs. However, others have found that lesions restricted to the BLA (Jellestad and Cabrera 1986; Vazdarjanova and McGaugh 1998; Ambrogi Lorenzini et al. 1991; Selden et al. 1991; Holahan and White 2002) do not disrupt active forms of avoidance while lesions restricted to the CeA impair active avoidance (Poremba and Gabriel 1997; Smith et al. 2001; Holahan and White 2002). While the lack of consistency of these effects does not eliminate the possibility that several different CRs could be mediated in different parts of the amygdala, it may suggest that the reported differences are due to experimental variables rather than anatomical-behavioral differences.

Another approach to understanding the mechanism by which the amygdala influences behavior is to postulate a single CR with a general effect. During the open door test, the normal rats that had been shocked during training moved between the compartments several times but spent most of their time in the neutral one. This behavior has been explained by an extension of the Pavlovian model, sometimes called two-factor theory (Mowrer 1947; Miller 1948; Rescorla and Solomon 1967; McAllister and McAllister 1995). The theory assumes that a conditioned response (CR) of some kind is acquired during training. This CR cannot be the avoidance behavior itself because there was no opportunity to perform that behavior during training when the door was closed. Therefore, the theory postulates the existence of an aversive conditioned internal response (CIR) that promotes avoidance of the conditioned cues as an instrumental behavior (Mowrer and Lamoreaux 1946; Mowrer 1947; Miller 1948). The CIR's existence as an aversive state is inferred from the instrumental behaviors it promotes (Mowrer 1947; Miller 1948; Brown and Jacobs 1949; Rescorla and Solomon 1967; Fanselow 1984; McAllister and McAllister 1995; Davis 1997; LeDoux 2000a).
The measure of avoidance used in the present study was time spent in the no-shock compartment. An increase in this time would involve escape from the shock compartment and a form of passive or inhibitory avoidance that prevents the rat from leaving the no-shock compartment. These two behaviors could be reinforced by the absence of the aversive conditioned cues in the shock compartment. Amygdala inactivation blocked the place avoidance observed in normal rats. The fact that this occurred in the presence of normal activity levels makes it unlikely that the effect was due to an inability to initiate or perform either of these behaviors. This constraint leads to the conclusion that amygdala inactivation blocked the hypothesized CIR that reinforces these behaviors, producing the avoidance response.

In addition to eliminating the avoidance response, amygdala inactivation also blocked freezing. Place avoidance requires the initiation of movement; freezing involves suppression of movement. Elevated freezing interferes with the ability of rats to initiate active (place) avoidance (Sidman 1962a,b; Anisman 1973; Anisman and Waller 1973; Holahan and White 2001). The elimination of both of these incompatible behaviors by amygdala inactivation is further evidence that its effects were due to elimination or attenuation of a CIR rather than impaired the ability to perform either of the observed behaviors. If amygdala inactivation impaired the ability to freeze, avoidance would not have been eliminated; if it impaired the ability to avoid, freezing would not have been affected. The alternative is that both behaviors were the result of the postulated CIR, which was eliminated by inactivation of the amygdala. Another manifestation of the CIR that is eliminated by amygdala lesions (Holahan and White 2002) and inactivation (Holahan and White 2004a) is conditioned memory modulation, an unobservable response that improves retention when activated during the posttraining period.

In the present experiment exposure to aversive unconditioned or conditioned stimuli tended to decrease movement (increased freezing, decreased crossovers) and amygdala inactivation reversed these effects, decreasing freezing and increasing crossovers. These findings are consistent with a long history of observations on the effects of amygdala manipulations on behavior. The first report of intracranial electrical stimulation in an awake animal (Hess 1957) described an "arrest" response with electrodes located in the amygdala. Kaada (1972) summarized subsequent investigations of this phenomenon and its obverse produced by amygdala lesions. In rats, it has been shown that amygdala lesions increase locomotion in an exploratory situation (White and Weingarten 1976) while amygdala stimulation decreases locomotion and increases freezing (Weingarten and White 1978). These findings suggest that one component of an amygdala-mediated aversive CIR could be the suppression of motor output.

CIRs are assumed to have specific physiological instantiations. Consistent with this idea, amygdala lesions are known to block the increase in a number of physiological responses observed following aversive conditioning (LeDoux et al. 1988; Roozendaal et al. 1991; Antoniadis and McDonald 2000; Borszcz and Leaton 2003). Likewise, chemical or electrical stimulation of the amygdala (Kapp et al. 1982; Iwata et al. 1987; Sanders and Shekhar 1991) elevates heart rate and blood pressure. Sanders and Shekhar (1991) found that intra-amygdala injections of a $\mathrm{GABA}_{\mathrm{A}}$ antagonist (bicuculline) elevated heart rate and blood pressure, and similar injections produced conditioned place avoidance (Thielen and Shekhar 2002). Activation of the amygdala GABA system, as in the present study, would block production of such internal responses reducing the occurrence of freezing and place avoidance. Future investigation may establish more direct relationships between such physiological conditioned responses and the observable behaviors they influence.

\section{Learning \& Memory}




\section{MATERIALS AND METHODS}

\section{Subjects}

Male, Long-Evans rats (Charles River; $\mathrm{n}=58$ ) weighed 250-300 g at the beginning of the experiment. They were singly housed in hanging wire cages with water freely available in a temperature $\left(21^{\circ} \mathrm{C} \pm 2^{\circ}\right)$ and light (on $700 \mathrm{hr}$ : off 1900) controlled room. The rats were treated in accordance with guidelines of the Canadian Council on Animal Care and protocols approved by the McGill University Animal Care and Use Committee.

\section{Surgery}

Rats deprived of food for $24 \mathrm{~h}$ were anaesthetized with an intraperitoneal injection of $65 \mathrm{mg} / \mathrm{kg}$ sodium pentobarbital and given $5 \mathrm{mg} / \mathrm{kg}$ atropine sulphate subcutaneously prior to standard stereotaxic surgery with the tooth bar set at $-3.5 \mathrm{~mm}$ (Paxinos and Watson 1998). Guide cannulas (26 ga, $11 \mathrm{~mm}$ length) were implanted at coordinates $\mathrm{AP}-2.5, \mathrm{ML} \pm 4.2, \mathrm{DV}-6.0 \mathrm{in} \mathrm{mm}$ from bregma and the skull surface. Each rat was then given an intramuscular injection of penicillin $(300,000$ units $/ \mathrm{ml})$ and placed into a heated holding cage. When recovery from anesthesia began, each rat was given $0.01 \mathrm{ml}$ Dipyrone (subcutaneous) to relieve post-surgical discomfort.

\section{Apparatus}

The shuttle-box consisted of two adjacent stainless steel compartments $(29 \times 28 \times 24 \mathrm{~cm})$ resting on two stainless steel catch pans $6 \mathrm{~cm}$ below the floor. The front walls were clear Plexiglas, the walls of one compartment were gray and the walls of the other were checkered black and white squares. There was a connecting vertical sliding door in the center of the common wall. The floors of each compartment consisted of $0.5 \mathrm{~cm}$ diameter stainless steel rods spaced $1.5 \mathrm{~cm}$ apart connected to shock generators. It was previously reported (Holahan and White 2002) that rats do not show any spontaneous unconditioned side preferences in this apparatus.

A passive infrared motion detector (Radio Shack, 49-550) modified to be optimally sensitive to the infrared wavelength emitted by rodents (R.E. Brown, pers. comm.) was mounted over a $6-\mathrm{cm}$ diameter hole in the top of each compartment. The detector responded to whole body movements, but not to small movements confined to the head or tail or to sniffing. The output of the detector was sampled 20 times per sec by a computer. If a movement was in progress at the time a sample was taken, a count was recorded. The counts were accumulated in 20-sec bins; the maximum count for each bin was 400 . An inactivity/freezing (I/F) score was calculated for each 20 -sec bin by subtracting the number of counts accumulated in the bin from 400. The scores were expressed as I/F per sec so that they could be compared across sessions of different durations.

The I/F score reflects a combination of the standard freezing measure (Bolles and Collier 1976; Fanselow 1980) and a certain amount of whole body inactivity that might not be included by strict application of the definition used by others. However, I/F and freezing measured by an observer are highly correlated over the entire range of freezing values (Holahan and White 2002; White and Salinas 2003). This was reconfirmed in the present experiment. During the test trials for the saline-injected rats an experimenter recorded freezing (absence of all body movements including sniffing, except for those produced by normal respiration) while the infrared detector recorded I/F. Each bout of freezing was timed and the total was used to calculate freezing as a percentage of the total session time $(360 \mathrm{sec})$. The correlation between observed freezing and the automatically recorded I/F was $0.97(\mathrm{~F}[1,4]=65.20, P<0.001)$ providing further validation that the I/F measure is highly similar to observed freezing.

The detectors were also used to determine the amount of time the rats spent in each compartment and the number of times they moved between the compartments (crossovers) during open door testing.

A third box (Box C; $29 \times 28 \times 24 \mathrm{~cm}$ ) was also used. This box was in the same room as the shuttle-box but was not attached to it. The frame of Box $\mathrm{C}$ was constructed from wood, the walls and ceiling were $1.0-\mathrm{cm}$ wire mesh, and the floor was a metal sheet.

\section{Handling}

The rats were allowed to recover from surgery for one week, during which they were handled on four consecutive days in the animal housing room. Eight to ten rats were placed into a large plastic tub with wood chips covering the floor for $2 \mathrm{~h}$. Each rat was held by the experimenter for $5 \mathrm{~min}$ per day. On the third handling day, each rat was given an intra-amygdala injection of saline. The stylets were removed and replaced with 32-ga injector cannulas connected via plastic tubing to a minipump. The injectors extended $1.5 \mathrm{~mm}$ beyond the guide cannulas. The experimenter held the rat while $1.0 \mu \mathrm{l}$ of saline was injected over $3 \mathrm{~min}$. After the injection, the stylets were replaced and the rats were put back into their home cages.

Food (30-35 g of standard pellets) was placed into each rat's cage approximately $4 \mathrm{~h}$ after the end of each day's procedures throughout the experiment.

\section{Pre-Exposure}

On each of the two days following handling, each rat was confined in Box C for 15 min. On the following day, each rat was randomly assigned to paired and unpaired compartments in the shuttle-box. When a compartment was paired, the rod floor was exposed; when it was unpaired, the rods were covered with a 0.5 $\mathrm{cm}$ wire mesh. The designation of the two compartments as paired and unpaired was counterbalanced within each experimental group. Each rat was confined in its paired compartment for $6 \mathrm{~min}$ and then immediately moved by the experimenter to its unpaired compartment for 6 min. During pre-exposure, the connecting door between the compartments was closed and no shocks were given.

\section{Pretraining Injections}

Twenty-four $\mathrm{h}$ after pre-exposure to the shuttle-box, 21 rats were given intra-amygdala saline or muscimol injections using the procedure described under the Handling section. Seven rats were injected with muscimol hydrobromide (Sigma; $0.44 \mathrm{nmol}$ free base weight/1.0 $\mu \mathrm{l} ; 1 \mu \mathrm{l}$ per side over $3 \mathrm{~min}$ ) and 14 rats were injected with the same volume of $0.9 \%$ saline. The injectors were left in place for 2 min following each injection.

Forty min after the injections, seven muscimol (train-mus) and seven saline (train-sal) rats were placed into their paired compartments. After 2 min (preshock phase) they were given four $0.5-\mathrm{s}, 1.0 \mathrm{~mA}$ footshocks (shock phase) with a 1 min intershock interval. The seven remaining saline-injected rats (con-sal) were placed into their paired compartments but were not given any shocks. The next day, all rats were placed into their unpaired compartments for 6 min with no injections and no shocks.

Twenty-four $\mathrm{h}$ after exposure to their unpaired compartments, each rat was placed into the shock-paired compartment with the connecting door between the compartments closed (test phase). The rats remained there for $6 \mathrm{~min}$ and the detector recorded $\mathrm{I} / \mathrm{F}$.

Twenty-four $\mathrm{h}$ after the closed-door test, all rats were placed into the shock-paired compartment with the connecting door between the compartments open. During the 12-min test, time in each compartment and the number of times the rats moved into and out of the paired compartment (crossovers) were recorded automatically by the detectors.

\section{Pretesting Injections}

Twenty-five rats were individually placed into their paired compartments and shocked as described for the pretraining groups. The remaining 12 rats were placed into their paired compartments but were not given any shocks. The next day, all rats were placed into their unpaired compartments for 6 min with no shocks. 
Twenty-four $\mathrm{h}$ after exposure to their unpaired compartments, the shocked rats were injected with muscimol (test-mus; $\mathrm{n}=12$ ) or saline (test-sal; $\mathrm{n}=13$ ). The 12 non-shocked rats (consal) were injected with saline.

Fifteen min following the injections, five rats in group testmus and six rats each in groups test-sal and con-sal were placed into their shock-paired compartments for 6 min with the connecting door between the compartments closed. I/F was recorded using the detectors.

The remaining seven rats in groups test-mus and test-sal and six rats in group con-sal were placed into the shock-paired compartment with the connecting door between the compartments open. Time in each compartment and crossovers between the compartments were recorded automatically during the 12-min test.

\section{Data Analysis}

I/F during the preshock and shock phases was measured during the shock-training session. I/F during the $120 \mathrm{sec}(6,20$-sec bins) before rats received shock in their paired compartments was labeled the "preshock" phase. I/F during the $240 \mathrm{sec}(12,20$-sec bins) when the rats received the four shocks was the "shock phase." The total I/F for each phase was divided by the duration of the phase to obtain an I/F per sec score. Similarly, total I/F for the 18 bins that comprised the 6 min closed-door test phase was summed and divided by 360 . The I/F per sec scores for the three phases were analyzed with two-way repeated measures ANOVAs (group by phase) and Fisher's least significant difference (LSD) post hoc tests (Maxwell and Delaney 1990).

The place avoidance test was the first time the rats were exposed to the open door configuration. In most normal, untreated rats, exposure to a novel environment elicits exploration (Barnett 1963). In the present case this led to discovery of the open door and escape from the shock-paired context. In some shocked rats injected with saline, freezing, and other forms of inactivity observed only during the first bout in the paired compartment impeded this behavior (Sidman 1962a; Baron 1964; Brener and Goesling 1970; Kumar 1970; Anisman 1973; Anisman and Waller 1973). This increased the duration of the first bout in the paired compartment for these rats, distorting the place avoidance measure. To obtain an uncontaminated measure of place avoidance, the data for this bout were removed from the total time in the paired compartment for all rats. Avoidance ratios were calculated as the total amount of time spent in the unpaired compartment minus the amount of time in the paired compartment (without the first paired bout) divided by the sum of these two times ([unpaired - paired] / [unpaired + paired]). The avoidance ratios were analyzed with a randomized one-way ANOVA and Fisher's LSD post hoc tests.

Movement between the two compartments was expressed as a crossover rate, defined as the total number of times a rat moved between the paired and unpaired compartments divided by the session time (sec) remaining after subtraction of the duration of the first bout in the paired compartment. In these calculations, the number of crossovers was reduced by one to correct for elimination of the first bout, which was ended by the first crossover. Crossover rates were analyzed with a randomized one-way ANOVA and Fisher's LSD post hoc tests.

\section{Histology}

Upon completion of the behavioral procedures, rats were overdosed with an intraperitoneal injection of $60 \mathrm{mg} / \mathrm{kg}$ chloral hydrate and perfused transcardially with saline followed by $10 \%$ formal-saline. Brains were post-fixed for approximately one week in formal-saline before being frozen and sectioned at $30 \mu \mathrm{m}$ through the implant tracks. Brain slices were mounted on gelatin-coated slides, allowed to air dry for $2 \mathrm{~d}$, and stained with thionin (Donovick 1974). Whole brain slices were digitally captured using Scion Image (Scion Corporation) and processed with CorelDraw.

\section{Assessment of c-Fos Expression}

To examine the area of inactivation produced by the intraamygdala muscimol injections, a subset of the rats given pretest- ing saline or muscimol injections ( $\mathrm{n}=$ four test-sal and four testmus) were sacrificed $90 \mathrm{~min}$ after the end of the closed-door test and their brains were processed for c-Fos protein immunohistochemistry using a procedure similar to that supplied by Oncogene Research Products (Protocol 1: Staining fos-induced formalin-fixed, floating rat brain sections with $c$-fos (Ab-5); courtesy of J. Elmquist and C.B. Saper). The primary antibody (polyclonal c-Fos Ab-5; 1: 50,000; lot \#D09803) was from Calbiochem. The secondary antibody (biotinylated anti-rabbit made in goat) and the avidin-biotin complex (ABC Elite Kit) were from Vector.

Every second brain section through the cannulae tracks from each rat was saved for thionin staining. This stain produced visible differentiation of the lateral/basolateral amygdala (LA/ BLA), the central amygdala (CeA), and the medial amygdala (MeA). The cells in the piriform cortex and the cortical amygdala were also visible. An image of a brain section just caudal to the injector track was captured and enlarged $4 \times$ using a microscope and imaging software. The region of interest was outlined on these images and transferred to the adjacent section, which had been processed for c-Fos. Labeled cells within these regions were counted by an experimenter without knowledge of the experimental group to which the brain sections belonged.

For each rat in the test-sal and test-mus groups, the c-Fos positive cells for the four regions in the left and right hemispheres were calculated as percentages of the mean counts for the test-sal group. This gave a mean of $100 \%$ for each region in the test-sal group and a variance around that mean. It also gave means and variances for each region in the test-mus group that could be compared to the means of the test-sal group using a three-way ANOVA with group (muscimol or saline) as the between factor and hemisphere (left or right) and region of interest (LA/BLA, CeA, MeA, cortical area) as repeated measures.

\section{ACKNOWLEDGMENTS}

This research was supported in part by a grant from the National Sciences and Engineering Research Council of Canada to N.M.W. M.R.H. was supported by a National Institutes of Health, National Research Service Award 5 F31 MH12369-04 from the National Institute of Mental Health.

The publication costs of this article were defrayed in part by payment of page charges. This article must therefore be hereby marked "advertisement" in accordance with 18 USC section 1734 solely to indicate this fact.

\section{REFERENCES}

Ambrogi Lorenzini, C., Bucherelli, C., Giachetti, A., Mugnai, L., and Tassoni, G. 1991. Effects of nucleus basolateralis amygdalae neurotoxic lesions on aversive conditioning in the rat. Physiol. Behav. 49: 765-770.

Ammassari-Teule, M., Pavone, F., Castellano, C., and McGaugh, J.L. 1991. Amygdala and dorsal hippocampus lesions block the effects of GABAergic drugs on memory storage. Brain Res. 551: 104-109.

Amorapanth, P., LeDoux, J.E., and Nader, K. 2000. Different lateral amygdala outputs mediate reactions and actions elicited by a fear-arousing stimulus. Nat. Neurosci. 3: 74-79.

Anisman, H. 1973. Effects of pretraining compatible and incompatible responses on subsequent one-way and shuttle-avoidance performance in rats. J. Comp. Physiol. Psychol. 82: 95-104.

Anisman, H. and Waller, T.G. 1972. Facilitative and disruptive effects of prior exposure to shock on subsequent avoidance performance. $J$. Comp. Physiol. Psychol. 78: 113-122.

. 1973. Effects of inescapable shock on subsequent avoidance performance: Role of response repertoire changes. Behav. Biol. 9: 331-355.

Antoniadis, E.A. and McDonald, R.J. 1999. Discriminative fear conditioning to context expressed by multiple measures of fear in the rat. Behav. Brain Res. 101: 1-13.

2000. Amygdala, hippocampus and discriminative fear conditioning to context. Behav. Brain Res. 108: 1-19.

Bailey, D.J., Kim, J.J., Sun, W., Thompson, R.F., and Helmstetter, F.J. 1999. Acquisition of fear conditioning in rats requires the synthesis of mRNA in the amygdala. Behav. Neurosci. 113: 276-282.

Barnett, S.A. 1963. Movement in the living space. In The rat: A study in behavior, pp. 15-33. Aldine Publishing Co., Chicago.

Baron, A. 1964. Suppression of exploratory behavior by aversive

\section{Learning \& Memory}


stimulation. J. Comp. Physiol. Psychol. 57: 299-301.

Bauer, E.P., Schafe, G.E., and LeDoux, J.E. 2002. NMDA receptors and L-type voltage-gated calcium channels contribute to long-term potentiation and different components of fear memory formation in the lateral amygdala. J. Neurosci. 22: 5239-5249.

Bindra, D. and Anchel, H. 1963. Immobility as an avoidance response, and its disruption by drugs. J. Exp. Anal. Behav. 6: 213-218.

Blanchard, R.J. and Blanchard, C. 1968. Escape and avoidance responses to a fear eliciting situation. Psychon. Sci. 13: 19-20.

. 1969. Crouching as an index of fear. J. Comp. Physiol. Psychol. 67: $370-375$.

Blanchard, R.J. and Blanchard, D.C. 1970a. Dual mechanisms in passive avoidance: I. Psychon. Sci. 19: 1-2.

. 1970b. Dual mechanisms in passive avoidance: II. Psychon. Sci. 19: 3-4.

Blanchard, D.C. and Blanchard, R.J. 1972. Innate and conditioned reactions to threat in rats with amygdaloid lesions. J. Comp. Physiol. Psychol. 81: 281-290.

Bolles, R.C. and Collier, A.C. 1976. The effect of predictive cues on freezing in rats. Anim. Learn. Behav. 4: 6-8.

Bolles, R.C. and Riley, A.L. 1973. Freezing as an avoidance response: Another look at the operant-respondent distinction. Learn. Motiv. 4: $268-275$.

Borszcz, G.S. and Leaton, R.N. 2003. The effect of amygdala lesions on conditional and unconditional vocalizations in rats. Neurobiol. Learn. Mem. 79: 212-225.

Bouton, M.E. and Bolles, R.C. 1980. Conditioned fear assessed by freezing and by the suppression of three different baselines. Anim. Learn. Behav. 8: 429-434.

Brener, J. and Goesling, W.J. 1970. Avoidance conditioning of activity and immobility in rats. J. Comp. Physiol. Psychol. 70: 276-280.

Brown, J.S. and Jacobs, A. 1949. The role of fear in the motivation and acquisition of responses. J. Exp. Psychol. 39: 747-759.

Brown, J.S., Kalish, H.I., and Farber, I.E. 1951. Conditioned fear as revealed by magnitude of startle response to an auditory stimulus. $J$. Exp. Psychol. 41: 317-328.

Cahill, L. and McGaugh, J.L. 1991. NMDA-induced lesions of the amygdaloid complex block the retention-enhancing effect of posttraining epinephrine. Psychobiology 19: 206-210.

Cahill, L., Weinberger, N.M., Roozendaal, B., and McGaugh, J.L. 1999. Is the amygdala a locus of "conditioned fear"? Some questions and caveats. Neuron 23: 327-328.

Cahill, L., Vazdarjanova, A., and Setlow, B. 2000. The basolateral complex is involved with, but is not necessary for, rapid acquisition of Pavlovian "fear conditioning." Eur. J. Neurosci. 12: 3044-3050.

Cahill, L., McGaugh, J.L., and Weinberger, N.M. 2001. The neurobiology of learning and memory: some reminders to remember. Trends Neurosci. 24: 578-581.

Campbell, B.A. and Campbell, E.H. 1962. Retention and extinction of learned fear in infant and adult rats. J. Comp. Physiol. Psychol. 55: $1-8$.

Davis, M. 1992. The role of the amygdala in conditioned fear. In The amygdala: Neurobiological aspects of emotion, memory, and mental dysfunction, (ed. J.P. Aggleton), pp. 255-305. Wiley-Liss, New York.

. 1997. Neurobiology of fear responses: The role of the amygdala. J. Neuropsychiatry Clin. Neurosci. 9: 382-402.

. 2000. The role of the amygdala in conditioned and unconditioned fear and anxiety. In The amygdala: Second edition: A functional analysis (ed. J.P. Aggleton), pp. 213-287. Oxford, Oxford University Press.

Decker, M.W., Curzon, P., and Brioni, J.D. 1995. Influence of separate and combined septal and amygdala lesions on memory, acoustic startle, anxiety, and locomotor activity in rats. Neurobiol. Learn. Mem. 64: 156-168.

Donovick, P.J. 1974. A metachromatic stain for neural tissue. Stain Tech. 49: 49-51.

Edeline, J.-M., Hars, B., Hennevin, E., and Cotillon, N. 2002. Muscimol diffusion after intracerebral microinjections: A reevaluation based on electrophysiological and autoradiographic quantifications. Neurobiol. Learn. Mem. 78: 100-124.

Fanselow, M.S. 1980. Conditional and unconditional components of postshock freezing. Pav. J. Biol. Sci. 15: 177-182.

. 1984. What is conditioned fear? Trends Neurosci. 7: 460-462.

Fanselow, M.S. and Gale, G.D. 2003. The amygdala, fear, and memory. Ann. N.Y. Acad. Sci. 985: 125-134.

Fanselow, M.S. and Kim, J.J. 1994. Acquisition of contextual Pavlovian fear conditioning is blocked by application of an NMDA receptor antagonist D,L-2-Amino-5-Phosphonovaleric Acid to the basolatera amygdala. Behav. Neurosci. 108: 210-212.

Fanselow, M.S. and LeDoux, J.E. 1999. Why we think plasticity underlying Pavlovian fear conditioning occurs in the basolateral amygdala. Neuron 23: 229-232.
Fendt, M. 2001. Injections of the NMDA receptor antagonist aminophosphonopentanoic acid into the lateral nucleus of the amygdala block the expression of fear-potentiated startle and freezing. J. Neurosci. 21: 4111-4115.

Fendt, M. and Fanselow, M.S. 1999. The neuroanatomical and neurochemical basis of conditioned fear. Neurosci. Biobehav. Rev. 23: $743-760$.

Gaston, M.G. and Freed, L. 1969. Effect of amygdaloid lesions in a fear conditioning situation not involving instrumental learning. Psychon. Sci. 16: $55-56$

Goldstein, M.L. 1960. Acquired drive strength as a joint function of shock intensity and number of acquisition trials. J. Exp. Psychol. 60: $349-358$.

. 1968. Effects of lesions of the amygdaloid complex on peripheral shock thresholds and activity in the hooded rat. J. Gen. Psychol. 79: 59-74.

Goosens, K.A. and Maren, S. 2001. Contextual and auditory fear conditioning are mediated by the lateral, basal, and central amygdaloid nuclei in rats. Learn. Mem. 8: 148-155.

Helmstetter, F.J. 1992. Contribution of the amygdala to learning and performance of conditional fear. Physiol. Behav. 51: 1271-1276.

Helmstetter, F.J. and Bellgowan, P.S. 1994. Effects of muscimol applied to the basolateral amygdala on acquisition and expression of contextual fear conditioning in rats. Behav. Neurosci. 108: $1005-1009$.

Hess, W.R. 1957. The functional organization of the diencephalon. Grune \& Stratton, New York.

Hiroi, N. and White, N.M. 1991. The amphetamine conditioned place preference: Differential involvement of dopamine receptor subtypes and two dopaminergic terminal areas. Brain Res. 552: 141-152.

Holahan, M.R. and White, N.M. 2001. Two-process learning theory and multiple memory systems. Abstr. Soc. Neurosci. 27: 743.2.

. 2002. Conditioned memory modulation, freezing, and avoidance as measures of amygdala-mediated conditioned fear. Neurobiol. Learn. Mem. 77: 250-275.

. 2003. Effect of muscimol inactivation of the basolateral or central amygdala on shock-conditioned responses. Ann. N.Y. Acad. Sci. 985: 525-527.

- 2004a. Amygdala inactivation blocks expression of conditioned memory modulation and the promotion of avoidance and freezing. Behav. Neurosci. 114: 25-35.

. 2004b. Amygdala c-Fos induction corresponds to unconditioned and conditioned aversive stimuli but not to freezing. Behav. Brain Res. 152: 109-120.

Iwata, J., Chida, K., and LeDoux, J.E. 1987. Cardiovascular responses elicited by stimulation of neurons in the central amygdaloid nucleus in awake but not anesthetized rats resemble conditioned emotional responses. Brain Res. 418: 183-188.

Jellestad, F.K. and Cabrera, I.G. 1986. Exploration and avoidance learning after ibotenic acid and radio frequency lesions in the rat amygdala. Behav. Neural Biol. 46: 196-215.

Kaada, B.R. 1972. Stimulation and ablation of the amygdala complex with reference to functional representation. In: The neurobiology of the amygdala (ed. B.F. Eleftheriou). Plenum, New York.

Kapp, B.S., Gallagher, M., Underwood, M.D., McNall, C.L., and Whitehorn, D. 1982. Cardiovascular responses elicited by electrical stimulation of the amygdala central nucleus in the rabbit. Brain Res. 234: $251-262$

Killcross, S., Robbins, T.W., and Everitt, B.J. 1997. Different types of fear-conditioned behaviour mediated by separate nuclei within the amygdala. Nature 388: 377-380.

Kim, J.J., Rison, R.A., and Fanselow, M.S. 1993. Effects of amygdala, hippocampus, and periacqueductal gray lesions on short- and long-term contextual fear. Behav. Neurosci. 107: 1093-1098.

Kumar, R. 1970. Effects of fear on exploratory behaviour in rats. Q. J. Exp. Psychol. 22: 205-214.

Lamprecht, R., Farb, C.R., and LeDoux, J.E. 2002. Fear memory formation involves p190 RhoGAP and ROCK proteins through a GRB2-mediated complex. Neuron 36: 727-738.

LeDoux, J.E. 1996. Emotional networks and motor control: A fearful view. In Progress in brain research (eds. G. Holstege et al.), pp. 437-446. Elsevier Science, San Diego.

. 1998. Fear and the brain: Where have we been, and where are we going? Biol. Psychiatry 44: 1229-1238.

2000a. The amygdala and emotion: a view through fear. In The amygdala: Second edition: A functional analysis (ed. J.P. Aggleton), pp. 289-310. Oxford University Press, Oxford.

2000b. Emotion circuits in the brain. Annu. Rev. Neurosci. 23: $155-184$.

LeDoux, J.E., Iwata, J., Cicchetti, P., and Reiss, D.J. 1988. Different projections of the central amygdaloid nucleus mediate autonomic and behavioral correlate of conditioned fear. J. Neurosci. 
8: 2517-2529.

Lee, Y., Walker, D.L., and Davis, M. 1996. Lack of a temporal gradient of retrograde amnesia following NMDA-induced lesions of the basolateral amygdala assessed with the fear-potentiated startle paradigm. Behav. Neurosci. 110: 836-839.

Lee, H.J., Choi, J.-S., Brown, T.H., and Kim, J.J. 2001. Amygdalar NMDA receptors are critical for the expression of multiple conditioned fear responses. J. Neurosci. 21: 4116-4124.

Maren, S. 1998. Overtraining does not mitigate contextual fear conditioning deficits produced by neurotoxic lesions of the basolateral amygdala. J. Neurosci. 18: 3088-3097.

. 1999. Neurotoxic basolateral amygdala lesions impair learning and memory but not the performance of conditional fear in rats. $J$. Neurosci. 19: 8696-8703.

. 2001. Neurobiology of Pavlovian fear conditioning. Annu. Rev. Neurosci. 24: 897-931.

. 2003. The amygdala, synaptic plasticity, and fear memory. Ann. N.Y. Acad. Sci. 985: 106-113.

Maren, S., Aharonov, G., and Fanselow, M.S. 1996a. Retrograde abolition of conditional fear after excitotoxic lesions in the basolateral amygdala of rats: absence of a temporal gradient. Behav. Neurosci. 110: 718-726.

Maren, S., Aharonov, G., Stote, D.L., and Fanselow, M.S. 1996b. $\mathrm{N}$-Methyl-D-Aspartate receptors in the basolateral amygdala are required for both acquisition and expression of conditional fear in rats. Behav. Neurosci. 110: $1365-1374$.

Martin, J.H. 1991. Autoradiographic estimation of the extent of reversible inactivation produced by microinjection of lidocaine and muscimol in the rat. Neuroscience 127: 160-164.

Maxwell, S.E. and Delaney, H.D. 1990. Designing experiments and analyzing data, pp. 170-206. Brooks/Cole Publishing Co, Pacific Grove, CA.

McAllister, W.R. and McAllister, D.E. 1962. Role of CS and of apparatus cues in the measurement of acquired fear. Psychol. Rep. 11: 749-756.

- 1971. Behavioral measurement of conditioned fear. In Aversive conditioning and learning (ed. F.R. Brush), pp. 105-179. Academic Press, New York.

- 1995. Two-factor fear theory: Implications for understanding anxiety-based clinical phenomena. In Theories of behavior therapy: Exploring behavior change (eds. W. O'Donohue and L. Krasner), pp. 145-171. American Psychological Association, Washington, DC.

Miller, N.E. 1948. Studies of fear as an acquirable drive: I. Fear as motivation and fear-reduction as reinforcement in the learning of new responses. J. Exp. Psychol. 38: 89-101.

Mowrer, O.H. 1947. On the dual nature of learning-A re-interpretation of "conditioning" and "problem-solving." Harv. Educ. Rev. 17: $102-148$.

Mowrer, O.H. and Lamoreaux, R.R. 1946. Fear as an intervening variable in avoidance conditioning. J. Comp. Psychol. 39: 29-50.

Muller, J., Corodimas, K.P., Fridel, Z., and LeDoux, J.E. 1997. Functional inactivation of the lateral and basal nuclei of the amygdala by muscimol infusion prevents fear conditioning to an explicit conditioned stimulus and to contextual stimuli. Behav. Neurosci. 111: 683-691.

Nader, K., Majidishad, P., Amorapanth, P., and LeDoux, J.E. 2001. Damage to the lateral and central, but not other, amygdaloid nuclei prevents the acquisition of auditory fear conditioning. Learn. Mem. 8: $156-163$.

Packard, M.G. and Cahill, L. 2001. Affective modulation of multiple memory systems. Curr. Opin. Neurobiol. 11: 752-756.

Packard, M.G. and Teather, L.A. 1998. Amygdala modulation of multiple memory systems: Hippocampus and caudate-putamen. Neurobiol. Learn. Mem. 69: 163-203.

Packard, M.G., Cahill, L., and McGaugh, J.L. 1994. Amygdala modulation of hippocampal-dependent and caudate nucleus-dependent memory processes. Proc. Natl. Acad. Sci. 91: 8477-8481.

Paxinos, G. and Watson, C. 1998. The rat brain atlas in stereotaxic coordinates. Academic Press, New York.

Phillips, R.G. and LeDoux, J.E. 1992. Differential contribution of amygdala and hippocampus to cued and contextual fear conditioning. Behav. Neurosci. 106: 274-285.

Poremba, A. and Gabriel, M. 1997. Amygdalar lesions block discriminative avoidance learning and cingulothalamic training-induced neuronal plasticity in rabbits. J. Neurosci. 17: 5237-5244.

Rescorla, R.A. and Solomon, R.L. 1967. Two-process learning theory:
Relationships between Pavlovian conditioning and instrumental learning. Psychol. Rev. 74: 151-182.

Roozendaal, B. and McGaugh, J.L. 1996. Amygdaloid nuclei lesions differentially affect glucocorticoid-induced memory enhancement in an inhibitory avoidance task. Neurobiol. Learn. Mem. 65: 1-8.

Roozendaal, B., Koolhaas, J.M., and Bohus, B. 1991. Attenuated cardiovascular, neuroendocrine, and behavioral responses after a single footshock in central amygdaloid lesioned male rats. Physiol. Behav. 50: 771-775.

Sacchetti, B., Baldi, E., Lorenzini, C.A., and Bucherelli, C. 2002. Cerebellar role in fear-conditioning consolidation. Proc. Natl. Acad. Sci. 99: 8406-8411.

Sanders, S.K. and Shekhar, A. 1991. Blockade of $\mathrm{GABA}_{\mathrm{A}}$ receptors in the region of the anterior basolateral amygdala of rats elicits increases in heart rate and blood pressure. Brain Res. 576: 101-110.

Schafe, G.E. and LeDoux, J.E. 2000. Memory consolidation of auditory Pavlovian fear conditioning requires protein synthesis and protein kinase A in the amygdala. J. Neurosci. 20: 1-5.

Schafe, G.E., Atkins, C.M., Swank, M.W., Bauer, E.P., Sweatt, J.D., and LeDoux, J.E. 2000. Activation of ERK/MAP kinase in the amygdala is required for memory consolidation of Pavlovian fear conditioning. $J$. Neurosci. 20: 8177-8187.

Schafe, G.E., Nader, K., Blair, H.T., and LeDoux, J.E. 2001. Memory consolidation of Pavlovian fear conditioning: A cellular and molecular perspective. Trends Neurosci. 24: 540-546.

Selden, N.R.W., Everitt, B.J., Jarrard, L.E., and Robbins, T.W. 1991. Complementary roles for the amygdala and hippocampus in aversive conditioning to explicit and contextual cues. Neuroscience 42: $335-350$.

Sidman, M. 1962a. Classical avoidance without a warning stimulus. J. Exp. Anal. Behav. 5: 97-104.

. 1962b. An adjusting avoidance schedule. J. Exp. Anal. Behav. 5: 271-277.

Smith, D.M., Monteverde, J., Schwartz, E., Freeman, J.H., and Gabriel, M. 2001. Lesions of the central nucleus of the amygdala: Discriminative avoidance learning, discriminative approach learning, and cingulothalamic training-induced neuronal activity. Neurobiol. Learn. Mem. 76: 403-425.

Steele, P.M. and Mauk, M.D. 1999. Inhibitory control of LTP and LTD: Stability of synapse strength. J. Neurophysiol. 81: 1559-1566.

Thielen, S.K. and Shekhar, A. 2002. Amygdala priming results in conditioned place avoidance. Pharmacol. Biochem. Behav. 71: $401-406$.

Vazdarjanova, A. and McGaugh, J.L. 1998. Basolateral amygdala is not critical for cognitive memory of contextual fear conditioning. Proc. Natl. Acad. Sci. 95: 15003-15007.

Vazdarjanova, A., Cahill, L., and McGaugh, J.L. 2001. Disrupting basolateral amygdala function impairs unconditioned freezing and avoidance in rats. Eur. J. Neurosci. 14: 709-718.

Viaud, M.D. and White, N.M. 1989. Dissociation of visual and olfactory conditioning in the neostriatum of rats. Behav. Brain Res. 32: 31-42.

Wang, S. and Redgrave, P. 1997. Microinjections of muscimol into lateral superior colliculus disrupt orienting and oral movements in the formalin model of pain. Neuroscience 81: 967-988.

Weingarten, H.P. and White, N.M. 1978. Exploration evoked by electrical stimulation of the amygdala of rats. Physiol. Psychol. 6: 229-235.

White, N.M. and McDonald, R.J. 1993. Acquisition of a spatial conditioned place preference is impaired by amygdala lesions and improved by fornix lesions. Behav. Brain Res. 55: 269-281.

. 2002. Multiple parallel memory systems in the brain of the rat. Neurobiol. Learn. Mem. 77: 125-184.

White, N.M. and Salinas, J.A. 2003. Mnemonic functions of the dorsal striatum and hippocampus in aversive conditioning. Behav. Brain Res. 142: 99-107.

White, N.M. and Weingarten, H.P. 1976. Effects of amygdaloid lesions on exploration by rats. Physiol. Behav. 17:73-79.

Wilensky, A.E., Schafe, G.E., and LeDoux, J.E. 1999. Functional inactivation of the amygdala before but not after auditory fear conditioning prevents memory formation. J. Neurosci. 19: 1-5.

. 2000. The amygdala modulates memory consolidation of fear-motivated inhibitory avoidance learning but not classical fear conditioning. J. Neurosci. 20: 7059-7066.

Received June 18, 2003; accepted in revised form May 12, 2004. 


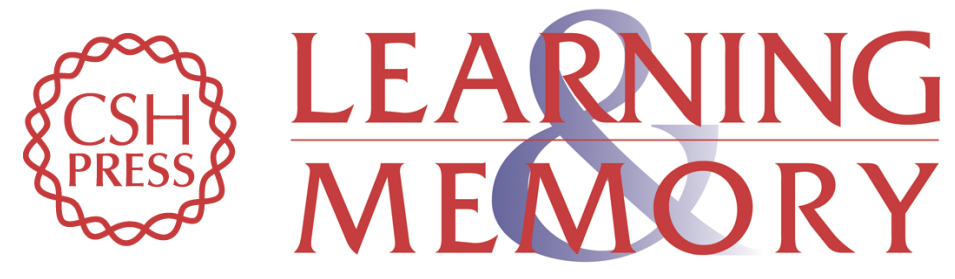

\section{Intra-Amygdala Muscimol Injections Impair Freezing and Place Avoidance in Aversive Contextual Conditioning}

Matthew R. Holahan and Norman M. White

Learn. Mem. 2004, 11:

Access the most recent version at doi:10.1101/lm.64704
Related Content Search Strategies Used by APP Transgenic Mice During Navigation in the Morris Water Maze
Christopher Janus
Learn. Mem. May, 2004 11: 337-346
References This article cites 100 articles, 16 of which can be accessed free at:
http://learnmem.cshlp.org/content/11/4/436.full.html\#ref-list-1
Articles cited in:
http://learnmem.cshlp.org/content/11/4/436.full.html\#related-urls
License
Email Alerting Receive free email alerts when new articles cite this article - sign up in the box at the Service top right corner of the article or click here.

